\title{
Leveraging the Final Project to Improve Student Motivation in Introductory Digital Design Courses
}

\author{
Andrew Danowitz \\ Department of Electrical Engineering \\ California Polytechnic State University \\ San Luis Obispo, California \\ Email: adanowit@calpoly.edu
}

\begin{abstract}
Student retention rates in engineering, especially among traditionally underrepresented groups, remain an obstacle to training a large, diverse engineering workforce. The NSF's Science and Engineering Indicators 2016 indicate that of students entering college with an intent to major in engineering, only $63 \%$ graduate with an engineering degree [1]. With research suggesting that misperceptions or a lack of knowledge about what work in a certain field is like can deter students from studying that discipline [2], [3], it is possible that providing a meaningful project experience at the introductory level could provide a strong positive impact on retention rates. This could be especially true for disciplines like Digital Design, where students of have little to no exposure to the discipline before starting college. This paper discusses my work to develop a representative design project for introductory digital design students with the goal of increasing retention.

My work uses the framework of Self-Determination Theory (SDT) [4] to design a project with the potential for increasing a student's intrinsic motivation for pursuing their studies in engineering and digital design in particular. I use adapted versions standard SDT survey instruments, such as the Perceived Competence for Learning Scale (PCS) [5] and the Self Regulation in Learning Questionnaire (SRQ-L) [6], to determine whether my project is having the desired effect and to what extent.

The preliminary results of my work show that my introductory digital design project improved one measure of Perceived Competence- "I feel confident in my ability to learn this material."-by almost $15 \%$ with a significance of $P=0.05$. There was no statistically significant change in student responses to the PCS as a whole, however, and the extent to which students experienced controlled regulation as measured by the SRQ-L was unchanged $(P=0.003)$.
\end{abstract}

\section{INTRODUCTION}

Because of a lack of exposure to the subject in primary and secondary education, introductory digital design classes must often focus on teaching students the mathematical and theoretical underpinnings of the subject. In a 10-week quarter system, this leaves little time for students to actively explore creative "design." This can have an adverse effect on recruiting students into the digital design curriculum. Several studies have shown that misconceptions or lack of knowledge about what work in a field is actually like can deter students from studying that discipline [2], [3]. Still other studies have demonstrated the importance of Project-Based Learning in encouraging students to persist in the field of engineering in general [7], [8], [9]. Without a solid introductory design experience to show them what building a real digital system is like, potentially interested students may be turned away from pursuing deeper studies in digital hardware.

Instructors have tried to address this problem by introducing a final project into introductory courses to give students a taste of system design. Anecdotal evidence suggests, however, that it can be difficult to create a design project that is both accessible to all students in the class, and open-ended enough to encourage students to push the limits of their digital design skills. To address this, I designed administered, and evaluated a team-based final project for California Polytechnic State University's "Digital Design" course. The project has student teams of three to four propose and build an interactive FPGAbased device that in some way helps to conserve natural resources.

As discussed in Section III, the project is intended to bolster student retention in the field of digital hardware design by meeting the key psychological needs for persistence outlined by Self Determination Theory (SDT): relatedness, competence, and autonomy [4].

The project was administered to two sections of Digital Design in 2015, and its effects on student motivation was evaluated using adapted versions of the Self-Determination Theory based Perceived Competence for Learning Scale (PCS) [5] and the Self-Regulation in Learning Questionnaire (SRQL) [6], as discussed in Sections IV and V.

While an analysis of the data shows that the project did substantially improve student confidence in their ability to learn the material, it did not change students' overall perceived competence, motivation, or attitudes towards pursuing the field of digital design. Sections $\mathrm{V}$ and VI attempt to analyze what this means for the project and future work.

\section{Self-Determination Theory}

Self-Determination Theory (SDT) is a psychological theory that explains how motivation is experienced in individuals [4]. Specifically, SDT defines two types of motivation: "autonomous" and "controlled". Autonomous motivation, is characterized by individuals completing tasks because they find the task fulfilling. This type of motivation is strongly associated with persistence. Controlled motivation is characterized by completing a task to satisfy external pressure, such as a demanding professor. People operating under controlled 
motivation are less likely to persist in a task once the external pressures are lifted. To effectively promote retention in digital design, or engineering in general, it is important for PBL to encourage autonomous motivation while minimizing controlled motivation.

According to Self-Determination Theory, educators (and others) can nurture autonomous motivation by meeting three key psychological needs of students: competence, autonomy, and relatedness [10]. Discussions of these three needs can be found in numerous SDT-based publications [10], [11], [12]. Briefly, however, feelings of competence can be supported in PBL by ensuring that a project is scoped so that it is both challenging and surmountable by all students in a course. It can also be augmented by receiving praise and recognition for quality work. Autonomy is generally nurtured by giving students choice in how they engage with, schedule, and complete the project. Conversely, autonomy can be harmed by offering tangible rewards for completing a project. Finally, relatedness can be improved by helping students develop supportive connections with others in relation to their work.

With these definitions in mind, Section III discusses how I developed my Digital Design project to encourage autonomous motivation in my students.

\section{Designing the Project}

The project I developed tasks the students to use their "FPGA and any external components [they] have to build something that helps to conserve natural resources." Students work in groups of three-to-four to complete the project.

I settled on the topic of conserving natural resources since sustainability is a major societal issue that students are familiar with, and should be and accessible to a broad population of students. The National Academy of Engineering suggests that communicating "the social context of engineering" can help improve the quality and appeal of an engineering education [8]. This dovetails with the goal of meeting students' SDTbased need of relatedness by putting their work into a positive social context. Requiring students to limit their design ideas to fit into the domain of sustainability, however, arguably strips students of a degree of autonomy. Unfortunately, I do not have data on whether this tradeoff affects student outcomes.

Outside of setting a domain for the project, the assignment is intentionally left open-ended to allow students to customize and individualize their designs. By giving students more control over what they build, open-ended projects should enhance feelings of autonomy. Also, since not all students in a course have the same level of understanding of the subject matter, open-ended projects allow each group to create a design that is both challenging and achievable, strengthening feelings of competence.

Since the prompt requires student designs to interact with the outside world, the project also encourages teams to explore external components, such as sensors, actuators, and other devices not covered in class. This encourages students to engage in self-directed learning and problem-solving within their groups, further adding to feelings of competence, relatedness, and autonomy.

Once assigned, the project is executed in a way to maximize student feelings of autonomy and competence. The only intermediate deliverable required of the project groups is a basic one-page project summary. I use this document to ensure that the student project is both sufficiently advanced and feasible to complete within the time available. After approving the projects, my role shifts from instructor to that of consultant: I offer students help and advice only when they request it. This allows students to meet their needs for autonomy and competence by giving them full ownership of the project process.

To further develop student feelings of competence and relatedness, students are encouraged to take advantage of peerinstruction. Students are permitted to discuss their work with other groups, and share lessons learned from implementing different features. To facilitate idea exchange outside of the classroom, I provide an online discussion forum for the project where students from all of my course sections can interact and answer each other's technical questions in an open environment. The hope is that by encouraging students in different groups and different sections to interact, I am encouraging the formation of supportive connections between students, and fostering a sense of relatedness. I also believe that peer instruction has an add-on effect of fostering competency in certain students by allowing them to take on the role of expert.

Finally, I designed the project deliverables in a way that I hoped would increase students' autonomous motivation. The last day of class is dedicated to a final project showcase, where student groups take turns briefly introducing their designs (5 minutes each), and spend the rest of the period trying demonstrations of their peers' projects. Students are able to increase their sense of relatedness as they socialize with their peers and get to see and appreciate each other's technical efforts.

In addition to the showcase, students are required to construct tutorials to teach digital design hobbyists and other engineers how to construct their devices. Students are then encouraged to publish their tutorials online at hobbyist sites like Instructables.com. By placing students in the role of instructor, the write-up allows students to feel an increased sense of competence in their digital design skills. More importantly, however, by encouraging students to publish their work on Instructables.com, they are introduced to a supportive communities of Makers, and through their online interactions have the opportunity to develop a sense of relatedness that can persist after the end of the course.

\section{Project Impact on Student Motivation}

To test the effects of the project on student motivation, I administered the project to two sections of Digital Design in Fall 2015. In total, there were fifteen projects submitted with students working in groups of three-to-four students. All groups submitted a functional project. 
TABLE I

SuRVEy QUESTIONS. PARTICIPANTS WERE ASKED TO RATE EACH ITEM AND ITS SUB-PARTS ON A LIKERT-SCALE OF 1 (NOT AT ALL TRUE) TO 7 (VERY TRUE).

\begin{tabular}{|c|}
\hline Perceived Competence Scale \\
\hline 1. I feel confident in my ability to learn this material. \\
\hline 2. I was capable of learning the material in this course. \\
\hline 3. I was able to achieve my goals in this course. \\
\hline 4. I felt able to meet the challenge of performing well in this course. \\
\hline Self-Regulation in Learning Questionnaire \\
\hline $\begin{array}{l}\text { 1. I will participate actively in future digital design course projects: } \\
\text { a. Because I feel like it's a good way to improve my skills and my } \\
\text { understanding of digital design. } \\
\text { b. Because others would think badly of me if I didn't. } \\
\text { c. Because learning digital design is an important part of } \\
\text { becoming an electrical engineer. } \\
\text { d. Because I would feel bad about myself if I didn't study this } \\
\text { approach. }\end{array}$ \\
\hline $\begin{array}{l}\text { 2. I am likely to follow my instructor's suggestions in future projects: } \\
\text { a. Because I would get a good grade if I do what he/she suggests. } \\
\text { b. Because I believe my instructor's suggestions will help improve } \\
\text { the final design. } \\
\text { c. Because I want others to think that I am a good digital designer. } \\
\text { d. Because it's easier to do what I'm told than to think about it. } \\
\text { e. Because it's important to me to do well at this. } \\
\text { f. Because I would probably feel guilty if I didn't comply with my } \\
\text { instructor's suggestions. }\end{array}$ \\
\hline $\begin{array}{l}\text { 3. The reason that I will continue to broaden my digital design skills is: } \\
\text { a. Because it's exciting to develop new digital systems. } \\
\text { b. Because I would feel proud if I did continue to improve at } \\
\text { digital design. } \\
\text { c. Because it's a challenge to really understand how complex } \\
\text { systems work. } \\
\text { d. Because it's interesting to use digital circuits to solve various } \\
\text { problems. }\end{array}$ \\
\hline Intent to Persist \\
\hline 1. I will consider a career in digital design \\
\hline 2. I plan to take elective coursework in the field of digital design \\
\hline 3. This course has increased my interest in digital design \\
\hline 4. The final project has increased my interest in digital design \\
\hline
\end{tabular}

With IRB approval, a survey instrument was created to measure the project's effects on student motivation and intent to persist in the field of digital design. The survey included adapted versions of the Perceived Competence for Learning Scale (PCS) [5] - a survey that measures how competent students feel about their ability to learn a subject—and an adapted version of the Self-Regulation in Learning Questionnaire (SRQ-L) [6] - a survey instrument designed to assess whether a student's motivation is more autonomous or controlled.

The instrument features 22 questions that ask students to state the extent to which they agree with each statement on a 7-point Likert scale. The full list questions is shown in Table I.

The survey was administered online to students twice, first in the days before the project was handed out $(t 1)$, and second

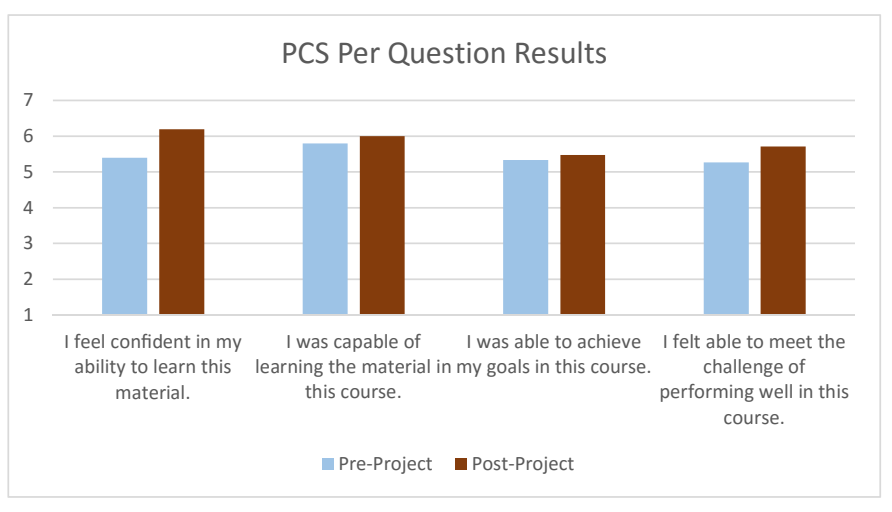

Fig. 1. Results on the PCS scale for pre- and post-project surveys. Note that only the change in responses to "I feel confident in my ability to learn this material" was found to be statistically significant. For pre-test $n=16$ and for post-test $n=22$.

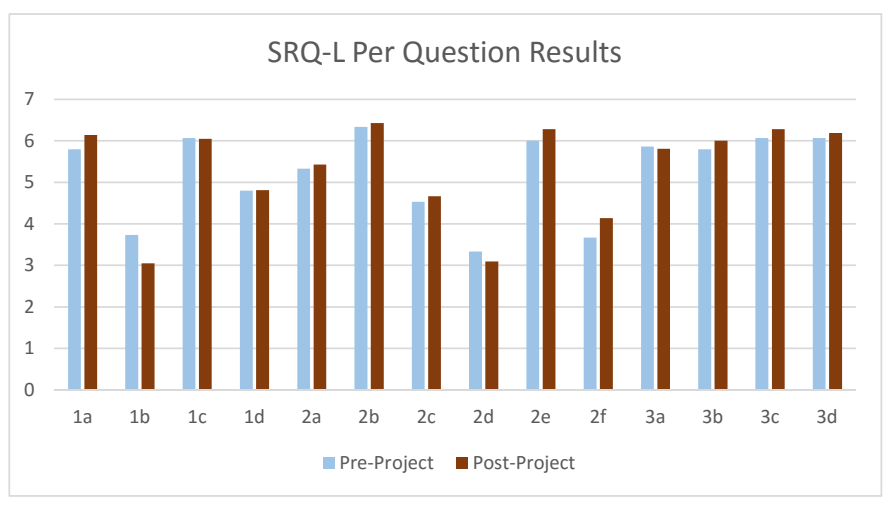

Fig. 2. Results on the SRQ-L scale for pre- and post-project surveys. Only the differences between the pre- and post- project responses to $1 \mathrm{c}$ and $1 \mathrm{~d}$ were found to be statistically significant in that they did not change over the course of the project. For pre-test $n=16$ and for post-test $n=22$.

after the project had been submitted ( $t 2)$. Despite the relatively short duration of the study, a pre- and post-test configuration was used to help control for any systematic biases students may have about the project itself. Student participation was entirely voluntary, and students were free to participate in any part of the survey.

Sixteen students participated in the $t 1$ survey and twentytwo students participated in the $t 2$ survey. The per-question survey results are shown in Figures 1-3. The aggregate scores for autonomous motivation, controlled motivation, and perceived competence are shown in Table II.

I ran a T-Test on each question to determine if the results at $t 2$ were statistically different from those at $t 1$. I also ran T-Tests to determine if there had been no statistical change in the results. From this analysis, I found that students reported a nearly $15 \%$ increase in their agreement with the statement "I feel confident in my ability to learn this material" from the PCS scale with $P=.05$. Conversely, student responses showed no change in their level of agreement with the statement "I will participate actively in future digital design 


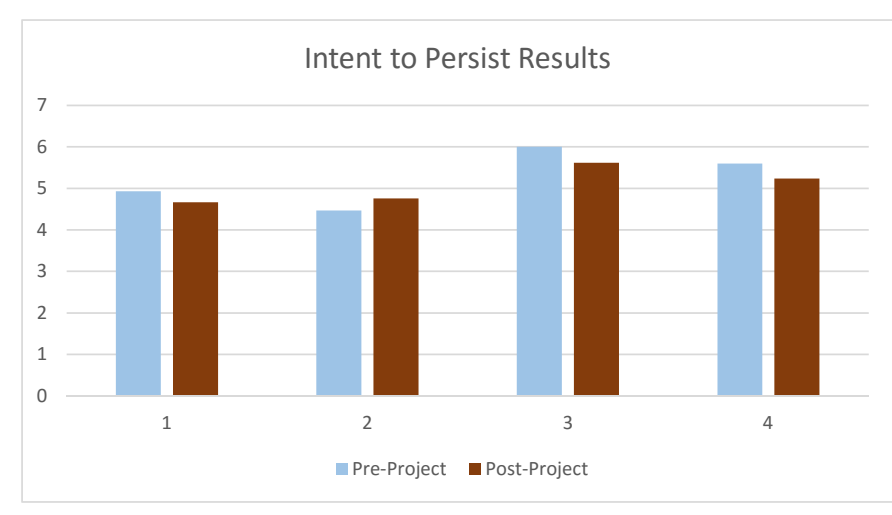

Fig. 3. Results to the questions regarding intent to persist in digital design. No question showed a statistically significant change between surveys. For pre-test $n=16$ and for post-test $n=22$.

TABLE II

AGgREGATE RESULTS OF SRQ-L AND PCS PORTIONS OF THE SURVEY INSTRUMENT. ONLY THE CONTROLLED MOTIVATION PROVIDED A STATISTICALLY SIGNIFICANT RESULT IN THAT IT DID NOT CHANGE BETWEEN THE TWO SURVEY PERIODS WITH $P=0.003$. FOR PRE-TEST $n=16$ AND FOR POST-TEST $n=22$.

\begin{tabular}{|l|c|c|}
\hline & Pre-Project $(n=16)$ & Post-Project $(n=22)$ \\
\hline Autonomous Motivation & 42 & 43 \\
\hline Controlled Motivation & 31 & 31 \\
\hline Perceived Competence & 5.5 & 5.8 \\
\hline
\end{tabular}

course projects because learning digital design is an important part of becoming an electrical engineer" with $P=0.05$. Students also showed no change on the statement "I will participate actively in future digital design course projects because I would feel bad about myself if I didn't study this approach" with a $P$ of roughly 0.01 . Finally, students showed no change on their aggregate controlled motivation score with $P=0.003$. No other questions or yielded statistically significantly results from the pre-project survey to the postproject survey. The results for students' aggregate scores for autonomous motivation, intent to persist in digital design, and overall perceived competence were similarly not statistically significant.

Section $\mathrm{V}$ discusses these results, and possible reasons for the large number of statistically insignificant changes.

\section{DISCUSSION}

The data indicates that the project increased students' confidence in their ability to learn digital design by $15 \%$ (from 5.4 to 6.2 out of 7 ). Additionally, the percentage of students who strongly agreed (responded 6 or 7 ) with the statement "I feel confident in my ability to learn this material" increased from sixty-seven percent to over ninety percent between the $t 1$ and $t 2$ measurements. While this measure did not directly translate into a statistically significant increase in measures of autonomous motivation or intent to persist in the field of digital design, it does indicate that, on average, students may feel more capable to learn the material in required follow-on courses.

That the other statistically significant results-students' belief that "learning digital design is an important part of becoming an electrical engineer," and overall extent of controlled motivation-showed no change between the measurements is less encouraging. For the "important part" question, responses at both measurement times averaged 6.1 , indicating that students already had a high opinion of the importance of digital design. In fact, the pre- and post-project aggregate scores for autonomous motivation, despite not showing a statistically significant change, are already quite high at 42 and 43 out of 49 respectively.

The fact that students had a score of 31 out of 49 on controlled motivation going into the project-demonstrating that they moderately-to-strongly identified with statements describing controlled motivation-could indicate that students had a pre-disposition for controlled motivation coming into the course. In fact, given that Digital Design is required of all Cal Poly Computer and Electrical Engineering majors, some students may have had no intrinsic interest in taking the course to begin with, and by extension, felt forced (controlled motivation) to take part in the course and the project.

Another issue that may have affected controlled motivation is the fact that students were not allowed to form their own groups for the project. Students were required to work in the same 3-4 person study groups that I assigned to them in the first week of class class. While many of these groups appeared to be highly functional, a few teams suffered from inter-personal conflicts and disengaged team-members, with conflicts largely coming to a head during the final project period. By sticking with the groups from the first week of class rather than allowing students to pick their own project partners, students, especially in the challenge groups, may have had some of their autonomy and relatedness stifled. Unfortunately, I did not control for these factors in my study, and can not quantify these effects.

The other major issue with this study, that a number of measures of motivation and persistance produced no statistically signficant results, seems less troubling given the small sample size $(n=16$ at $t 1)$. As I continue to refine this project and measure student responses, I hope to be able to generate a clearer picture of how my project affects these other measures of motivation.

\section{CONCLUSIONS}

I created an end-of-quarter project for an introductory digital design course that would improve student motivation to persist and student retention in the program. The project was designed to meet the three psychological needs identified by SelfDetermination Theory as key for developing autonomous motivation towards a task: competence, autonomy, and relatability.

I piloted this project with two sections of an introductory digital design course in Fall 2015, and measured the effects on student motivation using adapted versions of standard SDT questionnaires. The results showed that the project had 
improved students' confidence in their ability to learn Digital Design by $15 \%$, but had no effect on measures of controlled motivation and no statistically significant effectsy measures of autonomous motivation, and intent to persist in digital designs.

Ultimately, I believe that the $15 \%$ improvement in student's perceived ability to learn the material is a very positive result, and one that justifies the efforts to design a final project with SDT criteria in mind. The fact that perceived ability to learn the material did not correlate with a change in motivation or intent to persist in digital design points to the need for further research.

Reflecting on my experiences on running the course, I also believe that I may need to broaden the context of this study. When I initially developed the survey instrument, I only focused on tracking student motivation and intent to persist with regards to the field of digital design. Given the open-nature of the project assignment, however, many groups incorporated significant subsystems that fell outside of digital design, including the use Arduinos, motors and servos, and analog circuitry. As a result, I observed that several students engaged in the project without much of a focus on digital design at all. Anecdotally, one student who built a frontend of analog comparators and light sensors for his group's project told me that the course had solidified his intent to go into analog circuit design. For students like these, the project may have increased their motivation for studying electrical engineering in general even if it did not make them more motivated to pursue Digital Design. For future studies, it may be more appropriate to attempt to measure the impact of the project on student motivation and intent to persist in the major, rather than focus on a specific sub-discipline.

\section{ACKNOWLEDGMENT}

The author would like to thank the students who participated in this survey.

\section{REFERENCES}

[1] National Science Board, Science \& Engineering Indicators 2016. National Science Foundation, 2016, ch. 2.

[2] C. Alvarado and Z. Dodds, "Women in cs: an evaluation of three promising practices," in Proceedings of the 41st ACM technical symposium on Computer science education. ACM, 2010, pp. 57-61.

[3] L. Carter, "Why students with an apparent aptitude for computer science don't choose to major in computer science," ACM SIGCSE Bulletin, vol. 38, no. 1, pp. 27-31, 2006.

[4] R. M. Ryan and E. L. Deci, "Self-determination theory and the facilitation of intrinsic motivation, social development, and well-being." American psychologist, vol. 55, no. 1, p. 68, 2000.

[5] G. C. Williams and E. L. Deci, "Internalization of biopsychosocial values by medical students: a test of self-determination theory." Journal of personality and social psychology, vol. 70, no. 4, p. 767, 1996.

[6] A. E. Black and E. L. Deci, "The effects of instructors' autonomy support and students' autonomous motivation on learning organic chemistry: A self-determination theory perspective," Science education, vol. 84, no. 6 , pp. 740-756, 2000.

[7] R. A. Atadero, M. M. Balgopal, K. E. Rambo-Hernandez, and M. A. M. A. Casper, "Project-based learning in statics: Curriculum, student outcomes, and on-going questions," age, vol. 24, p. 1, 2014.

[8] Committee on the Engineer of 2020, Phase II, Committee on Engineering Education, and National Academy of Engineering, Educating the Engineer of 2020: Adapting Engineering Education to the New Century. National Academies Press, 2005.
[9] D. W. Knight, L. E. Carlson, and J. F. Sullivan, "Staying in engineering: Impact of a hands-on, team-based, first-year projects course on student retention," age, vol. 8, p. 1, 2003.

[10] M. Gagné and E. L. Deci, "Self-determination theory and work motivation," Journal of Organizational behavior, vol. 26, no. 4, pp. 331-362, 2005.

[11] D. Edward and R. Ryan, "Intrinsic motivation and self-determination in human behavior," New York: Pantheon, 1985.

[12] A. Danowitz, "Work-in-progress: Instructables.com as a tool to improve student outcomes and promote community engagement california polytechnic state university," in 2016 ASEE Pacific Southwest Conference. ASEE, 2016. 